\title{
Association of Plasma Pentraxin-3 Level with Lipid Levels and Cardiovascular Risk Factors in People with No History of Lipid- Lowering Medication: the Dong-gu Study
}

\author{
Ran Lee ${ }^{1}$, Hye-Ran Ahn², Min-Ho Shin ${ }^{1}$, Hee-Nam Kim ${ }^{1}$, Young-Hoon Lee ${ }^{3}$, Seong-Woo Choi ${ }^{4}$ and \\ Sun-Seog Kweon ${ }^{1,5}$
}

Ran Lee and Hye-Ran Ahn contributed equally to this work.

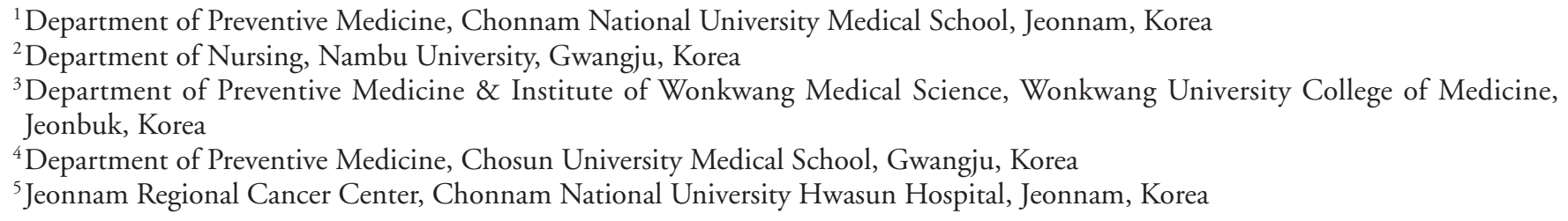

Aim: To elucidate the role of pentraxin-3 (PTX3) in atherosclerosis, we evaluated lipid and cardiovascular risk profiles according to the plasma PTX3 levels in subjects from the general population.

Methods: A sub-cohort of 2,000 subjects was randomly sampled from a Korean community-based cohort study. After excluding those with a medication history for dyslipidemia, 1,747 subjects (902 men and 845 women) were included in the final analyses. Linear and logistic regressions with adjustment for appropriate variables were performed.

Results: The PTX3 level was positively associated with the high-density lipoprotein cholesterol (HDL-C) level and negatively associated with the log-transformed triglyceride (TG) level, total cholesterol/HDL-C ratio, and low-density lipoprotein cholesterol (LDL-C)/HDL-C ratio $(p<0.05)$. Subjects with the highest PTX3 levels $(\geq$ $1.17 \mathrm{ng} / \mathrm{dl}$ ) exhibited a lower risk of metabolic syndrome (odds ratio [OR] $0.73,95 \%$ confidence interval [CI] 0.57-0.94), overweight/obesity (OR $0.65,95 \%$ CI $0.50-0.83$ ), increased TG level (OR $0.66,95 \%$ CI $0.51-$ 0.86), and increased HDL-C level (OR 0.67, 95\% CI 0.51-0.88) compared to those with the lowest PTX3 level $(<0.7 \mathrm{ng} / \mathrm{dl})$.

Conclusion: The circulating PTX3 level was inversely associated with metabolic syndrome, overweight/obesity, and parameters of dyslipidemia, suggesting a cardioprotective role of PTX3 in atherosclerosis.

\section{Introduction}

Cardiovascular disease (CVD) is the leading cause of mortality worldwide. According to the 2013 Global Burden of Disease study, 25.5\% of all deaths from 1990 to 2013 were attributable to $\mathrm{CVD}^{1}{ }^{1}$. The
World Health Organization speculated that approximately 20 million deaths from CVD occurred in 2015, which represents approximately $30 \%$ of the total number of deaths ${ }^{2}$. Atherosclerosis is the most important underlying cause of CVD, and its pathophysiology is closely linked to chronic or low-grade

Address for correspondence: Sun-Seog Kweon, Department of Preventive Medicine, Chonnam National University Medical School, 264 Seoyang-ro, Hwasuneup, Hwasun-gun, Jeonnam, Korea, 58128 E-mail: ujingogo@paran.com

Received: September 30, 2018 Accepted for publication: December 2, 2018 
inflammation ${ }^{3)}$. Identifying an inflammatory marker of atherosclerosis or predictor of CVD is a focus of research in medicine and public health ${ }^{4)}$. C-reactive protein (CRP) is a circulating, acute-phase reactant that reflects active systemic inflammation and is a marker of CVD ${ }^{5}$. Pentraxin-3 (PTX3) is structurally and functionally similar to CRP, is an essential component of innate immunity, and is correlated with various atherosclerosis surrogate markers. However, CRP and PTX3 reportedly play different roles in atherosclerosis and vascular function ${ }^{6}$. CRP is produced primarily by hepatocytes, while PTX3 is produced at inflammation sites by various cell types, including macrophages, smooth muscle cells, adipocytes, and endothelial cells, following stimulation by interleukin-1 or tumor necrosis factor- $\alpha^{7}$. Therefore, PTX3 is a more sensitive biomarker of vascular inflammation than CRP. PTX3 has been investigated as a potential predictor of several CVDs, including unstable angina pectoris ${ }^{8)}$, myocardial infarction $(\mathrm{MI})^{9)}$, and heart failure in stable coronary heart disease ${ }^{10)}$. Prospective studies have shown that PTX3 is positively associated with the risk ${ }^{11)}$ and prognosis ${ }^{12,13)}$ of, and mortality due to, CVD ${ }^{14)}$. However, studies of the role of PTX3 in atherosclerosis have reported conflicting results ${ }^{15-17)}$. In particular, the association between the level of PTX3 and dyslipidemia is unclear. PTX3 levels are reportedly higher in subjects with low high-density lipoprotein cholesterol (HDL-C) level and are positively associated with triglyceride (TG) levels in patients with metabolic syndrome (MS) ${ }^{18}$. Moreover, the PTX3 level is positively correlated with familial hypercholesterolemia ${ }^{19)}$. In vivo, an elevated HDL-C level is associated with increased PTX3 expression in vascular endothelial cells ${ }^{20)}$. However, in a multi-ethnic sub-cohort study, the PTX3 level was not associated with that of lipoproteins ${ }^{11}$.

In this study, we evaluated the association of the plasma PTX3 level with lipid profiles and CVD risk factors to compare the association with CRP among Korean participants in a community-based cohort study.

\section{Methods}

Subjects

The prospective Dong-gu Study evaluated the prevalence, incidence, and risk factors of chronic disease in urban area residents in Korea ${ }^{21,22)}$. A total of 9,260 urban residents participated in the baseline examination from 2007 to 2010 . Among them, 2,000 subjects were randomly selected for inclusion in this study. After excluding 253 subjects (12.6\%) who were consuming lipid-lowering medications at baseline or had a history of consuming lipid-lowering medication or had missing variables, 1,747 subjects (902 men and 845 women) were included in the analyses. All participants provided written informed consent. The study protocol conforms to the ethical guidelines of the 1975 Declaration of Helsinki and has been approved by the Institutional Review Board of Chonnam National University Hospital (no: I-008-05-05).

\section{PTX3 Assay}

The plasma PTX3 level was determined using a quantitative sandwich enzyme-linked immunosorbent assay kit (Quantikine R\&D International, MN, USA) according to the manufacturer's instructions. A streptavidin-coated plate was incubated with a biotinylated monoclonal antibody specific for human PTX3. The wells were washed, and pretreated standards and samples were added. After washing away any unbound substances, an enzyme-linked conjugate specific for human PTX3 was added. Subsequently, a substrate solution was added to induce color development, and the color intensity was measured. The PTX3 level (ng/ $\mathrm{mL}$ ) was determined using a standard curve. The minimum detectable dose (MDD) of PTX3 ranged from $0.007-0.116 \mathrm{ng} / \mathrm{mL}$ and the mean MDD was 0.025 $\mathrm{ng} / \mathrm{mL}$. The intra-assay coefficient of variation (CV) was $3.93 \%$ and the inter-assay CV was $5.06 \%$ according to the protocol. Reagents of the same lot numbers were used for all determinations to minimize the measurement variability. The assay was performed using plasma that had been stored at $-70{ }^{\circ} \mathrm{C}^{23)}$.

\section{Measurements of Variables}

Demographic factors and health habits (smoking, alcohol drinking, and regular exercise) were assessed using a questionnaire survey. Details of the anthropometric measurements, including height, weight, and waist and hip circumferences are provided elsewhere $^{21)}$. Lipid profiles, including total cholesterol (TC), TG, HDL-C, and low-density lipoprotein cholesterol (LDL-C) were analyzed by enzymatic assay using an automatic analyzer (Hitachi-7600; Hitachi, Japan). Dyslipidemia was defined as a TC level $\geq 200$ $\mathrm{mg} / \mathrm{dL}$, TG level $\geq 150 \mathrm{mg} / \mathrm{dL}$, LDL-C level $\geq 130$ $\mathrm{mg} / \mathrm{dL}$, and HDL-C level $<40 \mathrm{mg} / \mathrm{dL}$ in men or $<$ $50 \mathrm{mg} / \mathrm{dL}$ in women. The high-sensitivity CRP level was measured by latex-enhanced nephelometry using a high-sensitivity assay analyzer (Behring Nephelometer II; Dade-Behring Diagnostics, Marburg, Germany). White blood cells (WBCs) were enumerated using fresh ethylenediaminetetraacetic acid samples and a hematology analyzer (Micros 60; ABX, Montpellier, France) within 30 min of blood collection. The intima-media thickness of the carotid arterial wall 
(C-IMT) was measured by trained physicians using a B-mode ultrasound scanner. The status of plaque in the carotid arteries-including the common carotid artery, carotid bulb, and internal carotid artery-was determined based on the Mannheim IMT Consensus guidelines ${ }^{24)}$. Carotid plaque was defined as a focal structure that encroached into the lumen by at least $100 \%$ of the surrounding C-IMT value ${ }^{25)}$. Images were analyzed by one investigator using SigmaScan Pro software (SPSS, IL, USA) ${ }^{26)}$. Peripheral arterial disease (PAD) was defined as an ankle-brachial index $(\mathrm{ABI})<0.9$ assessed using a noninvasive, automatic oscillometric device (VP-1000, Colin, Tokyo, Japan) after $5 \mathrm{~min}$ of rest in the supine position. The brachial ankle pulse wave velocity (baPWV) also measured to evaluate the arterial stiffness using the same device, VP-1000. MS was defined according to the National Cholesterol Education Program, Adult Treatment Panel III ${ }^{27}$. The estimated glomerular filtration rate (eGFR) was evaluated using the Modification of Diet in Renal Disease equation, as follows: $186 \times$ (creatinine $\div 88.4)-1.154 \times($ age $)-0.203 \times(0.742$ if female $) \times$ (1.210 if black ${ }^{28)}$. The APOE genotype was categorized as E2 (E2E2 and E2E3), E3 (E3E3), or E4 (E3E4 and $E 4 E 4$ ) for allele-based analysis.

\section{Statistical Analysis}

The participants were classified into PTX3 and CRP level tertiles as follows: PTX3 low T, $<0.69 \mathrm{ng} /$ $\mathrm{mL}$; middle T, 0.70-1.16 ng/mL; and high T, 1.17$19.93 \mathrm{ng} / \mathrm{mL}$. The chi-squared test and analysis of variance (ANOVA) were used to evaluate differences in demographic and clinical characteristics, respectively, according to PTX3 tertile. Association of the PTX3 level with the lipid profile was evaluated by linear regression. Variables significantly associated with the PTX3 level in chi-square test or ANOVA were included in the regression models as covariates. Demographic variables, including age, body mass index (BMI), waist-hip ratio (WHR), and regular exercise were included in Model I. Model II comprised the Model I variables plus significant serological variables, including WBC, serum CRP concentrations, cortisol, albumin, urine creatinine level, and eGFR. Model III comprised the Model II variables plus clinical parameters of atherosclerotic change (maximal C-IMT, mean baPWV, and mean $\mathrm{ABI}$ ) and genetic variable of APOE alleles [E2, E3, and E4]). A multiple logistic regression was performed to evaluate the association between PTX3 and the intermediate atherosclerosis phenotypes (MS, high BMI $\left[\geq 25 \mathrm{~kg} / \mathrm{m}^{2}\right]$, thickened C-IMT [ $>1$ $\mathrm{mm}]$, presence of carotid plaque, elevated TG level $[\geq$ $150 \mathrm{mg} / \mathrm{dL}]$, and reduced HDL-C level $[<40 \mathrm{mg} / \mathrm{dL}$ in men or $<50 \mathrm{mg} / \mathrm{dL}$ in women]). Covariates, including age, sex, alcohol drinking, smoking, albumin, WBC, CRP, cortisol, urine creatinine, eGFR, and $A P O E$ genotype were inserted in the model. Logtransformed TG level values were used to reduce variance.

\section{Results}

The demographic and clinical characteristics of the subjects according to PTX3 level tertile are shown in Table 1. Those with a high PTX3 level were more likely to be older, exercise less frequently, and have a lower BMI and WHR. The PTX3 level did not differ according to sex, smoking, alcohol drinking, or history of consuming medication for hypertension or diabetes. Regarding clinical features, WBC count, serum levels of CRP, cortisol, albumin, maximal C-IMT, mean baPWV, mean ABI, urine creatinine concentration, and eGFR were associated with the PTX3 level. However, the systolic blood pressure and HbA1c level did not differ according to the PTX3 level. The PTX3 level was positively associated with the HDL-C level and negatively associated with the TG level, TC/HDL-C ratio, and LDL/HDL-C ratio (Table 1).

Table 2 shows the association between the PTX3 level and the lipid profile. After adjustment for all variables, the PTX3 level was positively associated with the HDL-C level and negatively associated with the log-transformed TG level, TC/HDL-C ratio, and LDL/HDL-C ratio. However, the PTX3 level was not significantly associated with the TC level, LDL-C level, maximal C-IMT, mean ABI, or mean baPWV (data not shown) (Table 2).

Table 3 shows the associations of the PTX3 level with the risk of MS, overweight/obesity, the intermediate phenotypes of atherosclerosis (thick C-IMT, PAD, arterial stiffness, and presence of carotid plaques), and dyslipidemia. We also compared the association of cardiovascular risk factors with PTX3 versus CRP. A high PTX3 level was associated with a decreased risk of MS, overweight/obesity, raised TG level, and reduced HDL-C level (OR [95\% CI], 0.73 [0.57-0.94], 0.65 [0.50-0.83], 0.66 [0.51-0.86], and 0.67 [0.51-0.88], respectively). However, the association of PTX3 with the CVD risk factors seems to be less than CRP (Table 3).

\section{Discussion}

Whether an increased circulating PTX3 level is atheroprotective or indicates the inflammation involved in advanced atherosclerosis is still unclear. To evaluate its role in atherosclerosis, and to reveal the 
Table 1. Baseline characteristics of subjects by plasma PTX3 levels

\begin{tabular}{|c|c|c|c|c|}
\hline & \multicolumn{4}{|c|}{ PTX3 tertile } \\
\hline & $\operatorname{Low}(n=582)$ & Middle $(\mathrm{n}=583)$ & $\operatorname{High}(n=582)$ & $p$-value \\
\hline Ranges of PTX3, ng/dl & $0.12-0.69$ & $0.70-1.16$ & $1.17-19.93$ & \\
\hline Men & $300(51.5)$ & $300(51.5)$ & $302(51.9)$ & 0.988 \\
\hline Regular exercise & $190(32.9)$ & $217(37.5)$ & $168(29.1)$ & 0.010 \\
\hline Alcohol drinking & $364(63.0)$ & 358 (61.6) & $329(56.8)$ & 0.080 \\
\hline Ever smoking & $229(39.6)$ & $228(39.2)$ & $233(40.2)$ & 0.947 \\
\hline HTN medication & $188(32.7)$ & $178(30.8)$ & $194(33.6)$ & 0.578 \\
\hline DM medication & $64(11.1)$ & $66(11.4)$ & $80(13.9)$ & 0.289 \\
\hline Metabolic syndrome & $328(56.6)$ & $312(53.6)$ & $299(51.8)$ & 0.264 \\
\hline APOE E4 allele & $84(14.6)$ & $110(19.2)$ & $94(16.3)$ & 0.109 \\
\hline Age (years) & $64.1 \pm 7.9$ & $65.5 \pm 8.3$ & $66.4 \pm 8.3$ & $<0.001$ \\
\hline WBC, $\left(\times 10^{3} / \mu \mathrm{L}\right)$ & $5.72 \pm 1.46$ & $5.87 \pm 1.58$ & $6.05 \pm 2.01$ & 0.005 \\
\hline BMI $\left(\mathrm{kg} / \mathrm{m}^{2}\right)$ & $24.5 \pm 2.7$ & $24.1 \pm 2.7$ & $23.8 \pm 2.9$ & 0.001 \\
\hline WHR & $0.94 \pm 0.05$ & $0.94 \pm 0.06$ & $0.95 \pm 0.06$ & 0.018 \\
\hline hsCRP (mg/dl) & $0.13 \pm 0.32$ & $0.15 \pm 0.45$ & $0.21 \pm 0.65$ & 0.014 \\
\hline Cortisol $(\mu \mathrm{g} / \mathrm{dL})$ & $9.18 \pm 3.34$ & $9.24 \pm 3.21$ & $8.77 \pm 3.62$ & 0.038 \\
\hline baPWV (cm/sec) & $1601 \pm 339$ & $1644 \pm 390$ & $1657 \pm 392$ & 0.028 \\
\hline Maximal IMT (mm) & $0.92 \pm 0.17$ & $0.90 \pm 0.19$ & $0.94 \pm 0.18$ & 0.001 \\
\hline Mean ABI & $1.12 \pm 0.08$ & $1.12 \pm 0.09$ & $1.12 \pm 0.09$ & 0.101 \\
\hline Urine creatinine & $112.7 \pm 63.2$ & $122.6 \pm 72.7$ & $135.1 \pm 79.6$ & $<0.001$ \\
\hline eGFR & $66.8 \pm 11.7$ & $66.0 \pm 11.6$ & $64.9 \pm 12.4$ & 0.026 \\
\hline Albumin & $4.49 \pm 0.30$ & $4.45 \pm 0.25$ & $4.45 \pm 0.30$ & 0.019 \\
\hline Systolic BP (mmHg) & $124.4 \pm 17.4$ & $124.0 \pm 16.9$ & $123.2 \pm 17.1$ & 0.524 \\
\hline HbA1c (\%) & $5.82 \pm 0.87$ & $5.80 \pm 0.89$ & $5.79 \pm 0.95$ & 0.894 \\
\hline TC (mg/dL) & $201.5 \pm 36.6$ & $197.9 \pm 38.4$ & $197.7 \pm 40.3$ & 0.160 \\
\hline $\mathrm{TG}(\mathrm{mg} / \mathrm{dL})$ & $151.3 \pm 103.8$ & $135.2 \pm 83.6$ & $133.6 \pm 136.3$ & 0.010 \\
\hline HDL-C (mg/dL) & $50.6 \pm 11.5$ & $50.7 \pm 11.2$ & $53.0 \pm 13.4$ & 0.001 \\
\hline LDL-C (mg/dL) & $120.7 \pm 35.0$ & $120.1 \pm 34.4$ & $117.9 \pm 39.1$ & 0.402 \\
\hline TC/HDL-C ratio & $4.14 \pm 1.03$ & $4.04 \pm 0.99$ & $3.90 \pm 1.04$ & $<0.001$ \\
\hline LDL/HDL ratio & $2.48 \pm 0.86$ & $2.46 \pm 0.81$ & $2.32 \pm 0.89$ & 0.003 \\
\hline
\end{tabular}

Values are given as count $(\%)$ or mean \pm standard deviation; $P$-values by chi-square test or analysis of variance test; HTN, hypertension; DM, diabetes; $A P O E$ genotype E3E4 and E4E4 were categorized into E4; WBC, white blood cell count; BMI, body mass index; WHR, waist-hip ratio; hsCRP, high sensitive C-reactive protein; baPWV, brachial-ankle pulse wave velocity; IMT, intima-media thickness; eGFR, estimated glomerular filtration rate; BP, blood pressure; HbA1c, hemoglobin A1c; TC, total cholesterol; TG, triglyceride; HDL-C, high-density lipoprotein cholesterol; LDL-C, low-density lipoprotein cholesterol; TC/HDL-C ratio, total cholesterol versus high-density lipoprotein cholesterol ratio; LDL/HDL-C ratio, low-density lipoprotein cholesterol versus low-density lipoprotein cholesterol ratio

Table 2. Relationship between PTX3 and lipid profiles among middle-aged and elderly Koreans with no lipid-lowering medication history

\begin{tabular}{|c|c|c|c|c|c|c|}
\hline & \multicolumn{2}{|c|}{ Model I } & \multicolumn{2}{|c|}{ Model II } & \multicolumn{2}{|c|}{ Model III } \\
\hline $\log T G$ & -0.077 & 0.002 & -0.080 & 0.001 & -0.088 & $<0.001$ \\
\hline LDL-C (mg/dL) & -0.004 & 0.862 & -0.021 & 0.379 & -0.015 & 0.532 \\
\hline HDL-C (mg/dL) & 0.100 & $<0.001$ & 0.113 & $<0.001$ & 0.110 & $<0.001$ \\
\hline
\end{tabular}

Values are given as coefficients and $P$-value by linear regression; Model I, adjusted for age, BMI, WHR and regular exercise; Model II, additionally adjusted for WBC, hsCRP, cortisol, urine creatinine, albumin, and eGFR; Model III, additionally adjusted maximal C-IMT, mean ABI, mean baPWV and APOE genotype; Log TG, log-transformed triglyceride; HDL-C, high-density lipoprotein cholesterol; LDL-C, low-density lipoprotein cholesterol; TC/HDL-C ratio, total cholesterol versus high-density lipoprotein cholesterol ratio; LDL/HDL-C ratio, low-density lipoprotein cholesterol versus high-density lipoprotein cholesterol ratio 
Lee et al.

Table 3. Comparison of the associations with cardiovascular risk profiles of PTX3 versus CRP

\begin{tabular}{|c|c|c|c|c|c|c|c|c|}
\hline & \multicolumn{4}{|c|}{ РTX3 } & \multicolumn{4}{|c|}{ CRP } \\
\hline & $\begin{array}{c}\text { Low } \\
(n=582)\end{array}$ & $\begin{array}{l}\text { Middle } \\
(n=583)\end{array}$ & $\begin{array}{c}\text { High } \\
(n=582)\end{array}$ & $\begin{array}{l}p \text {-value } \\
\text { for trend }\end{array}$ & $\begin{array}{c}\text { Low } \\
(n=599)\end{array}$ & $\begin{array}{l}\text { Middle } \\
(n=571)\end{array}$ & $\begin{array}{c}\text { High } \\
(n=576)\end{array}$ & $\begin{array}{l}p \text {-value } \\
\text { for trend }\end{array}$ \\
\hline Metabolic syndrome & 1 & $0.83(0.66-1.05)$ & $0.73(0.57-0.94)$ & 0.044 & 1 & $1.76(1.38-2.26)$ & $2.38(1.83-3.10)$ & $<0.001$ \\
\hline $\mathrm{BMI} \geq 25 \mathrm{~kg} / \mathrm{m}^{2}$ & 1 & $0.88(0.69-1.12)$ & $0.65(0.50-0.83)$ & 0.001 & 1 & $2.00(1.55-2.58)$ & $2.34(1.78-3.08)$ & $<0.001$ \\
\hline C-IMT > $>1.1 \mathrm{~mm}$ & 1 & $0.87(0.61-1.23)$ & $1.05(0.75-1.47)$ & 0.535 & 1 & $1.19(0.83-1.70)$ & $1.26(0.87-1.84)$ & 0.449 \\
\hline Carotid plaque & 1 & $0.93(0.73-1.21)$ & $0.98(0.76-1.27)$ & 0.872 & 1 & $1.02(0.79-1.33)$ & $1.12(0.84-1.48)$ & 0.723 \\
\hline $\mathrm{ABI} \leq 0.9$ & 1 & $0.93(0.36-2.39)$ & $0.77(0.29-2.10)$ & 0.876 & 1 & $2.01(0.59-6.82)$ & $3.74(1.09-12.8)$ & 0.099 \\
\hline Raised TG & 1 & $0.85(0.66-1.09)$ & $0.66(0.51-0.86)$ & 0.008 & 1 & $1.37(1.05-1.79)$ & $2.02(1.51-2.70)$ & $<0.001$ \\
\hline Reduced HDL-C & 1 & $0.88(0.68-1.15)$ & $0.67(0.51-0.88)$ & 0.014 & 1 & $1.46(1.11-1.93)$ & $1.88(1.41-2.51)$ & $<0.001$ \\
\hline Raised LDL-C & 1 & $0.86(0.67-1.09)$ & $0.84(0.65-1.07)$ & 0.313 & 1 & $1.29(1.01-1.67)$ & $1.34(1.03-1.75)$ & 0.058 \\
\hline
\end{tabular}

Multiple logistic regression adjusting for age, sex, alcohol drinking, smoking, albumin, WBC, CRP (or PTX3), cortisol, urine creatinine, eGFR and $A P O E$ genotype; raised TG defined as $\geq 150 \mathrm{mg} / \mathrm{dl}$; reduced HDL defined as $<40 \mathrm{mg} / \mathrm{dl}$ in men or $<50 \mathrm{mg} / \mathrm{dl}$ in women; raised LDL-C defined as $\geq 130 \mathrm{mg} / \mathrm{dl}$; C-IMT, carotid intima-media thickness; ABI, ankle-brachial index; TG, triglyceride; HDL-C, high-density lipoprotein cholesterol; LDL-C, low-density lipoprotein cholesterol

possible mechanism, we compared lipid profiles and cardiovascular risk factors according to the circulating PTX3 level in healthy subjects.

In this study, the PTX3 level was significantly positively associated with the HDL-C level and negatively associated with the TG level, TC/HDL ratio, and LDL/HDL ratio among the Korean subjects with no history of lipid-lowering medication. Moreover, the risk of MS and obesity were significantly lower in the highest PTX3 tertile compared to the lowest group. However, no association with hypertension, diabetes, intermediate atherosclerosis phenotypes in carotid and peripheral arteries, and lifestyle factors was found in this study. Thus, PTX3 is negatively associated with the cardiovascular risk factors of atherosclerosis, contrary to CRP, and this association is likely to involve lipid metabolism. Therefore, an increased circulating PTX3 level may be a protective response and may exert an anti-inflammatory effect in atherosclerosis. To our knowledge, no previous epidemiological study has reported an association of the circulating PTX3 level with lipid parameters and the risk of MS in subjects with no history of lipid-lowering medication.

PTX3, the prototype protein of the long pentraxin group, is an essential component of innate immunity. It is produced by immune cells and vascular cells in response to proinflammatory signals, such as cytokines, microbial components, and HDL-C and oxidized LDL-C ${ }^{20,29)}$. PTX3 production is rapidly induced in inflamed tissue and is released into plasma at the sites of atherosclerosis, vascular damage, or inflammation ${ }^{15}$. Therefore, a persistently elevated PTX3 level may be associated with morbidity due to, or the severity of, CVDs, including unstable angina pectoris ${ }^{8)}, \mathrm{MI}^{9)}$, and renal damage ${ }^{30)}$. In addition, the circulating PTX3 level is positively associated with risk factors for CVDs, including obesity ${ }^{31}$, low-HDL$\mathrm{C}$ and high fibrinogen ${ }^{32)}$, C-IMT and coronary artery calcification ${ }^{11)}$, arterial stiffness ${ }^{33)}$, and a reduced $\mathrm{eGFR}^{34)}$. The PTX3 level is elevated in patients with $\mathrm{MS}^{18,35)}$ and those with familial hypercholesterolemia ${ }^{19)}$; it indicates advanced atherosclerosis in patients with subclinical coronary stenosis ${ }^{36)}$. The PTX3 level in aortic wall tissue is correlated with the severity of coronary artery disease as well as various risk factors for atherosclerosis among patients who underwent coronary artery bypass graft surgery ${ }^{33)}$. These findings suggest that PTX3 may be a useful biomarker of inflammatory or atherosclerotic $\mathrm{CVD}^{37}$. PTX3 reportedly delays atherosclerosis progression. In vivo, plasma PTX3 levels were significantly increased in mice injected with HDL. Moreover, HDL modulated the mRNA level of PTX3 and protein secretion by human umbilical vein endothelial cells and human aortic endothelial cells in a dosedependent manner. However, it did not alter the expression of the short pentraxin CRP and serum amyloid $\mathrm{P}$ component ${ }^{20)}$. Prior reports indicate its deficiency is associated with vascular inflammation ${ }^{38)}$, neointimal hyperplasia after vascular injury ${ }^{39,40)}$, and $\mathrm{MI}^{41)}$, which supports the cardiovascular protective role of PTX3. In human studies, the plasma PTX3 level was negatively associated with $\mathrm{BMI}^{42)}, \mathrm{TG}^{43)}$, and fat body mass ${ }^{7,42)}$, and positively associated with the adiponectin level ${ }^{42,44,45)}$ and glucose-stimulated insulin secretion ${ }^{45)}$. In longitudinal studies, decreased BMI and fat mass were associated with an increased serum PTX3 level ${ }^{42,46)}$. In addition, the plasma PTX3 level is an independent predictor of left-ventricle dys- 
function and mortality in MI patients with ST elevation ${ }^{47)}$. The discrepancies among the study findings may be due to their analysis of relatively few subjects and/or selection bias caused by including disease-specific populations ${ }^{42}$. Therefore, we analyzed a large number of subjects in a community-based cohort study and excluded users of lipid-lowering drugs to enhance the generalizability of the results. In our study, the PTX3 level was negatively associated with an elevated TG level as well as a reduced HDL-C level, TC/HDL-C ratio, LDL/HDL-C ratio, and risk of MS. Therefore, PTX3 is negatively associated with the cardiovascular risk factors of atherosclerosis and, thus, may play a protective role in CVD development.

PTX3 has complex effects in the vasculature and is involved in multiple pathways. It has similar properties to the anti-inflammatory and antidiabetic adipokine, adiponectin. Circulating PTX3 and adiponectin may dampen or enhance inflammation by similar modes of action ${ }^{42}$. Oxidative stress may affect PTX3 production by adipocytes in obese individuals, and in MI patients, the level of PTX3 is correlated with several markers of oxidative stress ${ }^{47}$. PTX3 inhibits the classical complement pathway by blocking the interaction of $\mathrm{Clq}$ with immunoglobulins ${ }^{48)}$, thereby reducing tissue injury. Expression of PTX3 is regulated by HDL-C ${ }^{20)}$ and a decrease in the HDL-C level may explain the lower PTX3 level in obese individuals ${ }^{44)}$. HDL-induced PTX3 expression in the endothelium, which is dependent on the PI3K/Akt pathway, may explain the vascular-protective effect of PTX3 ${ }^{20,49)}$. PTX3 has several advantages compared to CRP as a biomarker of CVDs risk. Circulating PTX3 is a faster responding biomarker in cardiovascular pathologies ${ }^{50)}$ and a better predictor of CVD risk than CRP ${ }^{36}$. Plasma concentration of PTX3 peaked earlier than that of CRP among patients with acute MI (AMI). Maximal PTX3 concentration was reached within 6 hours, and CRP was reached 48 hours after onset of chest pain ${ }^{9)}$. In our results, PTX3 showed lower performance than CRP, so the combination of PTX3 and CRP can provide a better tool for CVDs risk prediction.

The main strength of the present study was the relatively large sample size and inclusion in the analysis of numerous clinical variables. The subjects were a general population sampled from a community-based cohort, and those with dyslipidemia were excluded from the analysis to enhance the results generalizability. This study also had limitations. First, because of the cross-sectional design, we could not determine the causality of the relationships of the circulating PTX3 level with the lipid profile or the risk of CVD. Second, the biologic and functional relevance of the above-mentioned relationships were not evaluated. Finally, although the association between PTX3 and lipid profiles is statistically significant, the beta values seem to be small, indicating that the contribution of PTX3 for predicting these lipid levels is relatively small.

In conclusion, the plasma PTX3 level was positively associated with the HDL-C level and negatively associated with the TG level, risk of MS, overweight/ obesity, and dyslipidemia. Our study provides additional evidence, especially from community-based study, that PTX3 plays an atheroprotective role and may be a simple biomarker of CVD risk. Further studies are required to elucidate the mechanism by which PTX3 influences the cardiovascular system.

\section{Conflict of Interests}

The authors declare that they have no conflict of interest.

\section{Author Contributions}

Kweon SS, conceptualization and data analysis; Lee R, manuscript writing; Ahn HR, laboratory work and financial support; Kim HN, laboratory work support; Shin MH, Choi SW and Lee YH, cohort data collection; and all authors approved the final manuscript.

\section{Acknowledgments}

This research was supported by National Research Foundation of Korea (NRF) funded by the Ministry of Science (grant number: 2017R1C1B5016174)

\section{References}

1) Mortality GBD and Causes of Death C: Global, regional, and national age-sex specific all-cause and cause-specific mortality for 240 causes of death, 1990-2013: a systematic analysis for the Global Burden of Disease Study 2013. Lancet, 2015; 385: 117-171

2) In: Promoting Cardiovascular Health in the Developing World: A Critical Challenge to Achieve Global Health, ed by Fuster V and Kelly BB, Washington (DC), 2010

3) Frostegard J: Immunity, atherosclerosis and cardiovascular disease. BMC Med, 2013; 11: 117

4) Montagnana M, Lippi G, Salvagno GL, Franchini M, Targher G and Guidi GC: [Role of biochemical risk factors and markers for the risk of atherosclerosis]. Recenti progressi in medicina, 2008; 99: 215-222

5) Pearson TA, Mensah GA, Alexander RW, Anderson JL, Cannon RO, 3rd, Criqui M, Fadl YY, Fortmann SP, Hong Y, Myers GL, Rifai N, Smith SC, Jr., Taubert K, 
Tracy RP, Vinicor F, Centers for Disease C, Prevention and American Heart A: Markers of inflammation and cardiovascular disease: application to clinical and public health practice: A statement for healthcare professionals from the Centers for Disease Control and Prevention and the American Heart Association. Circulation, 2003; 107: 499-511

6) Vilahur G and Badimon L: Biological actions of pentraxins. Vascul Pharmacol, 2015; 73: 38-44

7) Miyamoto T, Rashid Qureshi A, Heimburger O, Barany P, Carrero K, Sjoberg B, Lindholm B, Stenvinkel P and Carrero JJ: Inverse relationship between the inflammatory marker pentraxin-3, fat body mass, and abdominal obesity in end-stage renal disease. Clin J Am Soc Nephrol, 2011; 6: 2785-2791

8) Inoue K, Sugiyama A, Reid PC, Ito Y, Miyauchi K, Mukai S, Sagara M, Miyamoto K, Satoh H, Kohno I, Kurata T, Ota H, Mantovani A, Hamakubo T, Daida $\mathrm{H}$ and Kodama T: Establishment of a high sensitivity plasma assay for human pentraxin3 as a marker for unstable angina pectoris. Arterioscler Thromb Vasc Biol, 2007; 27: 161-167

9) Peri G, Introna M, Corradi D, Iacuitti G, Signorini S, Avanzini F, Pizzetti F, Maggioni AP, Moccetti T, Metra M, Cas LD, Ghezzi P, Sipe JD, Re G, Olivetti G, Mantovani $A$ and Latini R: PTX3, A prototypical long pentraxin, is an early indicator of acute myocardial infarction in humans. Circulation, 2000; 102: 636-641

10) Tazaki R, Tanigawa J, Fujisaka T, Shibata K, Takeda Y, Ishihara T, Hoshiga M, Hanafusa $T$ and Ishizaka $N$ : Plasma Pentraxin3 Level Is Associated With Plaque Vulnerability Assessed by Optical Coherence Tomography in Patients With Coronary Artery Disease. Int Heart J, 2016; 57: 18-24

11) Jenny NS, Blumenthal RS, Kronmal RA, Rotter JI, Siscovick DS and Psaty BM: Associations of pentraxin 3 with cardiovascular disease: the Multi-Ethnic Study of Atherosclerosis. J Thromb Haemost, 2014; 12: 999-1005

12) Altay S, Cakmak HA, Kemaloglu Oz T, Ozpamuk Karadeniz F, Turer A, Erer HB, Kilic GF, Keles I, Can G and Eren M: Long-term prognostic significance of pentraxin-3 in patients with acute myocardial infarction: 5-year prospective cohort study. Anatol J Cardiol, 2017; 17: 202209

13) Latini R, Maggioni AP, Peri G, Gonzini L, Lucci D, Mocarelli P, Vago L, Pasqualini F, Signorini S, Soldateschi D, Tarli L, Schweiger C, Fresco C, Cecere R, Tognoni G, Mantovani A and Lipid Assessment Trial Italian Network I: Prognostic significance of the long pentraxin PTX3 in acute myocardial infarction. Circulation, 2004; 110: 2349-2354

14) Dubin R, Li Y, Ix JH, Shlipak MG, Whooley M and Peralta CA: Associations of pentraxin-3 with cardiovascular events, incident heart failure, and mortality among persons with coronary heart disease: data from the Heart and Soul Study. Am Heart J, 2012; 163: 274-279

15) Norata GD, Garlanda C and Catapano AL: The long pentraxin PTX3: a modulator of the immunoinflammatory response in atherosclerosis and cardiovascular diseases. Trends in cardiovascular medicine, 2010; 20: 35-40

16) Shiraki A, Kotooka N, Komoda H, Hirase T, Oyama JI and Node K: Pentraxin-3 regulates the inflammatory activity of macrophages. Biochem Biophys Rep, 2016; 5 : 290-295

17) Klouche M, Peri G, Knabbe C, Eckstein HH, Schmid FX, Schmitz G and Mantovani A: Modified atherogenic lipoproteins induce expression of pentraxin-3 by human vascular smooth muscle cells. Atherosclerosis, 2004; 175: 221-228

18) Zanetti M, Bosutti A, Ferreira C, Vinci P, Biolo G, Fonda M, Valente M, Cattin L, Guarnieri G and Barazzoni R: Circulating pentraxin 3 levels are higher in metabolic syndrome with subclinical atherosclerosis: evidence for association with atherogenic lipid profile. Clinical and experimental medicine, 2009; 9: 243-248

19) Zanetti M, Zenti M, Barazzoni R, Zardi F, Semolic A, Messa MG, Mearelli F, Russi G, Fonda M, Scarano L, Bonora $\mathrm{E}$ and Cattin L: HELP LDL apheresis reduces plasma pentraxin 3 in familial hypercholesterolemia. PloS one, 2014; 9: e101290

20) Norata GD, Marchesi P, Pirillo A, Uboldi P, Chiesa G, Maina V, Garlanda C, Mantovani A and Catapano AL: Long pentraxin 3, a key component of innate immunity, is modulated by high-density lipoproteins in endothelial cells. Arterioscler Thromb Vasc Biol, 2008; 28: 925-931

21) Kweon SS, Shin MH, Jeong SK, Nam HS, Lee YH, Park KS, Ryu SY, Choi SW, Kim BH, Rhee JA, Zheng W and Choi JS: Cohort Profile: The Namwon Study and the Dong-gu Study. Int J Epidemiol, 2014; 43: 558-567

22) Lee YH, Shin MH, Choi JS, Rhee JA, Nam HS, Jeong SK, Park KS, Ryu SY, Choi SW, Kim BH, Oh GJ and Kweon SS: HbA1c is significantly associated with arterial stiffness but not with carotid atherosclerosis in a community-based population without type 2 diabetes: The Dong-gu study. Atherosclerosis, 2016; 247: 1-6

23) Lee R, Ahn HR, Shin MH, Kim HN, Lee YH, Choi SW and Kweon SS: Association between Plasma Pentraxin 3 Levels and Bone Mineral Density in Elderly Koreans: the Dong-gu Study. J Korean Med Sci, 2018; 33: e165

24) Touboul PJ, Hennerici MG, Meairs S, Adams H, Amarenco P, Bornstein N, Csiba L, Desvarieux M, Ebrahim S, Fatar M, Hernandez Hernandez R, Jaff M, Kownator S, Prati P, Rundek T, Sitzer M, Schminke U, Tardif JC, Taylor A, Vicaut E, Woo KS, Zannad F and Zureik M: Mannheim carotid intima-media thickness consensus (2004-2006). An update on behalf of the Advisory Board of the 3rd and 4th Watching the Risk Symposium, 13th and 15th European Stroke Conferences, Mannheim, Germany, 2004, and Brussels, Belgium, 2006. Cerebrovasc Dis, 2007; 23: 75-80

25) Kweon SS, Lee YH, Shin MH, Choi JS, Rhee JA, Choi SW, Ryu SY, Kim BH, Nam HS, Jeong SK and Park KS: Effects of cumulative smoking exposure and duration of smoking cessation on carotid artery structure. Circ J, 2012; 76: 2041-2047

26) Schiller NB, Shah PM, Crawford M, DeMaria A, Devereux R, Feigenbaum H, Gutgesell H, Reichek N, Sahn D, Schnittger I and et al.: Recommendations for quantitation of the left ventricle by two-dimensional echocardiography. American Society of Echocardiography Committee on Standards, Subcommittee on Quantitation of Two-Dimensional Echocardiograms. J Am Soc Echo- 
cardiogr, 1989; 2: 358-367

27) Grundy SM, Brewer HB, Jr., Cleeman JI, Smith SC, Jr., Lenfant C, National Heart L, Blood I and American Heart A: Definition of metabolic syndrome: report of the National Heart, Lung, and Blood Institute/American Heart Association conference on scientific issues related to definition. Arterioscler Thromb Vasc Biol, 2004; 24: e1318

28) Levey AS, Coresh J, Balk E, Kausz AT, Levin A, Steffes MW, Hogg RJ, Perrone RD, Lau J, Eknoyan G and National Kidney F: National Kidney Foundation practice guidelines for chronic kidney disease: evaluation, classification, and stratification. Ann Intern Med, 2003; 139: 137-147

29) Magrini E, Mantovani A and Garlanda C: The Dual Complexity of PTX3 in Health and Disease: A Balancing Act? Trends Mol Med, 2016; 22: 497-510

30) Sun H, Tian J, Xian W, Xie T and Yang X: Pentraxin-3 Attenuates Renal Damage in Diabetic Nephropathy by Promoting M2 Macrophage Differentiation. Inflammation, 2015; 38: 1739-1747

31) Miyaki A, Maeda S, Yoshizawa M, Misono M, Sasai H, Shimojo N, Tanaka $\mathrm{K}$ and Ajisaka R: Is pentraxin 3 involved in obesity-induced decrease in arterial distensibility? J Atheroscler Thromb, 2010; 17: 278-284

32) Alberti L, Gilardini L, Zulian A, Micheletto G, Peri G, Doni A, Mantovani A and Invitti C: Expression of long pentraxin PTX3 in human adipose tissue and its relation with cardiovascular risk factors. Atherosclerosis, 2009; 202: 455-460

33) Kasai $T$, Inoue $K$, Kumagai $T$, Kato $M$, Kawana F, Sagara $M$, Ishiwata $S$, Ohno $M$, Yamaguchi T, Momomura $S$ and Narui K: Plasma pentraxin 3 and arterial stiffness in men with obstructive sleep apnea. Am J Hypertens, 2011; 24: 401-407

34) Dubin R, Shlipak M, Li Y, Ix J, de Boer IH, Jenny N and Peralta CA: Racial differences in the association of pentraxin-3 with kidney dysfunction: the Multi-Ethnic Study of Atherosclerosis. Nephrol Dial Transplant, 2011; 26: 1903-1908

35) Kardas F, Akin L, Kurtoglu S, Kendirci M and Kardas Z: Plasma Pentraxin 3 as a biomarker of metabolic syndrome. Indian J Pediatr, 2015; 82: 35-38

36) Vukovic-Dejanovic V, Bogavac-Stanojevic N, Spasic S, Spasojevic-Kalimanovska V, Kalimanovska-Ostric D, Topalovic M and Jelic-Ivanovic Z: Association of Serum Pentraxin-3 and High-Sensitivity C-Reactive Protein with the Extent of Coronary Stenosis in Patients Undergoing Coronary Angiography. J Med Biochem, 2015; 34: 440449

37) Inoue $K$, Kodama $T$ and Daida $H$ : Pentraxin 3: a novel biomarker for inflammatory cardiovascular disease. Int J Vasc Med, 2012; 2012: 657025

38) Norata GD, Marchesi P, Pulakazhi Venu VK, Pasqualini F, Anselmo A, Moalli F, Pizzitola I, Garlanda C, Mantovani A and Catapano AL: Deficiency of the long pentraxin PTX3 promotes vascular inflammation and atherosclerosis. Circulation, 2009; 120: 699-708

39) Inoue K: The cardioprotective role of pentraxin 3. J Atheroscler Thromb, 2015; 22: 335-337

40) Ishino M, Shishido T, Suzuki S, Katoh S, Sasaki T,
Funayama A, Netsu S, Hasegawa H, Honda S, Takahashi $\mathrm{H}$, Arimoto T, Miyashita T, Miyamoto T, Watanabe T, Takeishi Y and Kubota I: Deficiency of Long Pentraxin PTX3 Promoted Neointimal Hyperplasia after Vascular Injury. J Atheroscler Thromb, 2015; 22: 372-378

41) Salio M, Chimenti S, De Angelis N, Molla F, Maina V, Nebuloni M, Pasqualini F, Latini R, Garlanda C and Mantovani A: Cardioprotective function of the long pentraxin PTX3 in acute myocardial infarction. Circulation, 2008; 117: 1055-1064

42) Witasp A, Carrero JJ, Michaelsson K, Ahlstrom H, Kullberg J, Adamsson V, Riserus U, Larsson A, HelmerssonKarlqvist J, Lind L, Stenvinkel P and Arnlov J: Inflammatory biomarker pentraxin 3 (PTX3) in relation to obesity, body fat depots and weight loss. Obesity (Silver Spring), 2014; 22: 1373-1379

43) Yamasaki K, Kurimura M, Kasai T, Sagara M, Kodama $T$ and Inoue K: Determination of physiological plasma pentraxin 3 (PTX3) levels in healthy populations. Clinical chemistry and laboratory medicine, 2009; 47: 471-477

44) Ogawa T, Kawano $Y$, Imamura T, Kawakita K, Sagara M, Matsuo T, Kakitsubata Y, Ishikawa T, Kitamura K, Hatakeyama K, Asada Y and Kodama T: Reciprocal contribution of pentraxin 3 and C-reactive protein to obesity and metabolic syndrome. Obesity (Silver Spring), 2010; 18: $1871-1874$

45) Osorio-Conles O, Guitart M, Chacon MR, MaymoMasip E, Moreno-Navarrete JM, Montori-Grau M, Naf S, Fernandez-Real JM, Vendrell J and Gomez-Foix AM: Plasma PTX3 protein levels inversely correlate with insulin secretion and obesity, whereas visceral adipose tissue PTX3 gene expression is increased in obesity. Am J Physiol Endocrinol Metab, 2011; 301: E1254-1261

46) Bosutti A, Malaponte G, Zanetti M, Castellino P, Heer $\mathrm{M}$, Guarnieri G and Biolo G: Calorie restriction modulates inactivity-induced changes in the inflammatory markers C-reactive protein and pentraxin-3. J Clin Endocrinol Metab, 2008; 93: 3226-3229

47) Tomandlova M, Jarkovsky J, Tomandl J, Kubkova L, Kala P, Littnerova S, Gottwaldova J, Kubena P, Ganovska E, Poloczek M, Spinar J, Mueller C, Mebazaa A, Pavkova Goldbergova M and Parenica J: Prognostic value of pentraxin-3 level in patients with STEMI and its relationship with heart failure and markers of oxidative stress. Dis Markers, 2015; 2015: 159051

48) Nauta AJ, Bottazzi B, Mantovani A, Salvatori G, Kishore U, Schwaeble WJ, Gingras AR, Tzima S, Vivanco F, Egido J, Tijsma O, Hack EC, Daha MR and Roos A: Biochemical and functional characterization of the interaction between pentraxin 3 and C1q. Eur J Immunol, 2003; 33: 465-473

49) Norata GD, Callegari E, Marchesi M, Chiesa G, Eriksson $\mathrm{P}$ and Catapano AL: High-density lipoproteins induce transforming growth factor-beta2 expression in endothelial cells. Circulation, 2005; 111: 2805-2811

50) Soeki T, Niki T, Kusunose K, Bando S, Hirata Y, Tomita N, Yamaguchi K, Koshiba K, Yagi S, Taketani Y, Iwase T, Yamada H, Wakatsuki T, Akaike M and Sata M: Elevated concentrations of pentraxin 3 are associated with coronary plaque vulnerability. J Cardiol, 2011; 58: 151-157 